\title{
The Fibroblast Growth Factor Receptor-1 Is Necessary for the Induction of Neurite Outgrowth in PC12 Cells by aFGF
}

\author{
Hsien-Yi Lin, ${ }^{1}$ Jingsong Xu, ${ }^{4}$ David M. Ornitz, ${ }^{4}$ Simon Halegoua, ${ }^{3}$ and Michael J. Hayman ${ }^{2}$ \\ ${ }^{1}$ Biochemistry and Molecular Biology Graduate Program, ${ }^{2}$ Department of Molecular Genetics and Microbiology, and \\ ${ }^{3}$ Department of Neurobiology and Behavior, Institute of Cell and Developmental Biology, State University of New York at \\ Stony Brook, Stony Brook, New York 11794, and 4Department of Molecular Biology and Pharmacology, Washington \\ University Medical School, St. Louis, Missouri 63110-8103
}

The PC12 subclone, fnr-PC12 cells, is defective in neurite outgrowth in response to acidic fibroblast growth factor (aFGF); however, its response to nerve growth factor (NGF) is normal. Examination of the expression of FGF receptors (FGFRs) revealed that although PC12 cells express FGFR-1, -3 , and -4 , fnr-PC12 cells have a reduced level of expression of FGFR-1 but not FGFR-3 and -4 . Transfection of FGFR-1 into fnr-PC12 cells efficiently restored aFGF-induced neurite outgrowth, whereas transfection of FGFR-3 was much less efficient. Transfection of a chimeric receptor consisting of the extracellular domain of FGFR-3 fused to the transmembrane and intracellular domain of FGFR-1, termed FR31b, efficiently restored aFGFinduced neurite outgrowth. This demonstrates that the difference between these two receptors in their ability to induce neurite outgrowth is attributable to differences in the signaling capacity of their cytoplasmic domains. Activation of the chimeric receptor by aFGF induced a stronger and more persistent increase in the tyrosine phosphorylation of cellular proteins than did activation of FGFR-3 alone. In particular, the activation of MAP kinase by FR31b was more persistent than when activated by FGFR-3. This difference in signaling potential of FGFR-1 and -3 in fnr-PC12 cells may account for the difference in the potential for induction of neurite outgrowth. These results demonstrate that FGF-induced neurite outgrowth in PC12 cells occurs mainly via FGFR-1 and not via the other FGFRs expressed in these cells.

Key words: aFGF; FGFR-1; FGFR-3; neurite outgrowth; PC12 cells; fnr-PC12 cells; tyrosine phosphorylation; MAP kinase
The fibroblast growth factor (FGF) family of growth factors has diverse effects during embryonic development (for reviews, see Basilico and Moscatelli, 1992; Mason, 1994). In the nervous system, FGFs exhibit neurotrophic properties similar to those of the neurotrophins (for reviews, see Baird, 1994; Eckenstein, 1994), but their actions on nerve cells have been difficult to ascertain because they also affect glial cells (Engele and Bohn, 1991). Injection of FGF into the CNS of lesioned animals causes neurotrophic effects and stimulates the regeneration of lesioned axons (Anderson et al., 1988; Lipton et al., 1988; Cordeiro et al., 1989; Sasaki et al., 1992; MacMillan et al., 1993a,b; Nakata et al., 1993). In primary cell culture, FGFs mediate the survival, proliferation, and differentiation of both central and peripheral neurons and promote expression of neuronal characteristics (Morrison et al., 1986; Walicke et al., 1986; Schubert et al., 1987; Unsicker et al., 1987; Eckenstein et al., 1990; Sendtner et al., 1991; Ghosh and Greenberg, 1995; Vicario-Abejón et al., 1995). FGFs also stimulate the proliferation of peripheral sympathoadrenal precursors and induce responsiveness to nerve growth factor (NGF) (Birren and Anderson, 1990).

FGF actions are mediated by the binding and activation of FGF

\footnotetext{
Received March 6, 1996; revised May 3, 1996; accepted May 14, 1996.

This work was supported by National Institutes of Health Public Service Grants CA28146 and CA42573 (M.J.H.), CA60673 (D.M.O.), and NS18218 (S.H.). We thank the various members of our laboratories for helpful comments on this manuscript. We are also grateful to Drs. R. Davis, B. Druker, M. Jaye, M. Goldfarb, and R. Nishi for their invaluable gifts of reagents.

Correspondence should be addressed to Michael J. Hayman, Department of Molecular Genetics and Microbiology, State University of New York at Stony Brook, Stony Brook, NY 11794-5222.

Copyright (C) 1996 Society for Neuroscience $0270-6474 / 96 / 164579-09 \$ 05.00 / 0$
}

receptor (FGFR) tyrosine kinases. FGFRs are a gene family of four members (for review, see Jaye et al., 1992; Partanen et al., 1992; Johnson and Williams, 1993) termed FGFR-1 (flg), FGFR-2 (bek), FGFR-3, and FGFR-4. Expression patterns of FGFRs in the nervous system suggest that FGFs may have differential effects on distinct neuronal cell types throughout development. FGFR-1, -2 , and -3 are expressed differentially in subsets of neurons within both the peripheral nervous system (PNS) and the CNS as well as in glial cells (Heuer et al., 1990; Wanaka et al., 1990; Thompson et al., 1991; Asai et al., 1993; Peters et al., 1993; Yazaki et al., 1994). During the development of the chick nervous system, FGFR-1 is transiently expressed on different neuronal cell types but in a manner reciprocal with that of the NGF receptor (Heuer et al., 1990). In some neuronal cell types, co-expression of FGFRs and neurotrophin receptors is observed (Claude et al., 1988; Stemple et al., 1988). Thus it has been suggested that the FGFs act coordinately with the neurotrophins to guide neuronal development. Localization of the four different FGFRs on neuronal cell types is complex (Heuer et al., 1990; Wanaka et al., 1990; Thompson et al., 1991; Asai et al., 1993; Peters et al., 1993; Yazaki et al., 1994), making it difficult to elucidate the physiological role for a specific FGFR. FGF activity is complicated further by selective binding to different FGFRs (Jaye et al., 1992; Ornitz and Leder, 1992; Partanen et al., 1992; Johnson and Williams, 1993; Chellaiah et al., 1994). Consequently, the roles of each FGFR in the nervous system are still not known.

The PC12 cell line has provided a useful model for studying the actions of neurotrophins (Greene and Tischler, 1982). These cells respond to FGFs and NGF by the elaboration of a sympathetic neuron-like phenotype (Togari et al., 1985; Rydel and Greene, 
1987). The mechanisms of NGF and FGF action on PC12 cells seem to use similar signal transduction pathways for neurite outgrowth, beginning with the activation of a receptor tyrosine kinase and using a signaling cascade involving src, ras, raf, and the MAP kinases (Kremer et al., 1991; Thomas et al., 1992; D'Arcangelo and Halegoua, 1993; Wood et al., 1993). The FGFRs that mediate FGF actions on PC12 cells, however, have not been well characterized. Here we analyze FGFR expression and function in PC12 cells. Using a PC12 subline that is nonresponsive to FGF, we demonstrate that although PC12 cells normally express FGFR-1, -3, and -4, the FGF-nonresponsive cells no longer express high levels of FGFR-1. The levels of FGFR-3 and -4 are similar in both cell types. By transfection of FGFR-1 or -3 into the FGF-nonresponsive subline, we determined that only activation of FGFR-1 leads to high-efficiency neurite outgrowth. These data indicate that FGF-induced neurite outgrowth in PC12 cells occurs primarily via FGFR-1 and not via the other FGFRs expressed in PC12 cells. These studies provide a first step toward elucidating the actions of FGF through specific FGFRs expressed in neurons.

\section{MATERIALS AND METHODS}

Cell culture and growth factors. fnr-PC12 (also named GR-5) cells are a subclone of PC12 cells (Greene and Tischler, 1976) isolated and kindly provided by Rae Nishi (Oregon Health Sciences University, Portland, $\mathrm{OR})$. PC12, fnr-PC12, and fnr-PC12-derived transfectant lines were grown on tissue culture dishes in DMEM (Life Technologies, Grand Island, NY) supplemented with $10 \%$ donor horse serum (JRH Biosciences, Lenexa, KS), 5\% fetal bovine serum (JRH Biosciences), and 1\% penicillin/streptomycin (Life Technologies) in an atmosphere of $10 \%$ $\mathrm{CO}_{2}$ at $37^{\circ} \mathrm{C}$. Recombinant human aFGF (Jaye et al., 1988) and $\left[{ }^{125} \mathrm{I}\right] \mathrm{aFGF}$ were kindly provided by Michael Jaye (Rhône-Poulenc Rorer Central Research, Collegeville, PA). $\beta$-NGF was purified from mouse submaxillary glands (Mobley et al., 1976).

To assay for neurite outgrowth, cells were grown on tissue-culture plastic coated with a solution of polylysine $(25 \mu \mathrm{g} / \mathrm{ml})$ (Sigma, St. Louis, MO) and laminin $(10 \mu \mathrm{g} / \mathrm{ml})$ (Collaborative Research, Bedford, MA). The cells were plated at $\sim 10^{4}$ cells $/ 35 \mathrm{~mm}$ dish and treated with either 50 $\mathrm{ng} / \mathrm{ml}$ aFGF [plus $5 \mathrm{U} / \mathrm{ml}$ heparin (Upjohn, Kalamazoo, MI)] or $50 \mathrm{ng} / \mathrm{ml}$ NGF. Cells were scored positive for neurites if growth cone-containing neurites of at least two cell body diameters in length were observed.

Plasmids and transfection. The human FGFR-1 expression vector pFlgFL24 was kindly provided by Michael Jaye (Rhône-Poulenc Rorer Central Research). This vector consists of full-length human FGFR-1 cDNA (Dionne et al., 1990) in the eukaryotic expression vector pMJ30 (Jaye et al., 1988). The human FGFR-3 expression vector pLhR3-5 consists of full-length human FGFR-3 cDNA (Keegan et al., 1991) in the retroviral vector pLNCX (Miller and Rosman, 1989). Mo/FR31b/IRES expression vector consists of cDNA encoding a chimeric receptor with the extracellular domain of mouse FGFR-3 IIIb (Chellaiah et al., 1994) and the transmembrane domain and intracellular domain of mouse FGFR-1 (Yayon et al., 1991). Mo/FR3IIIbs/IRES expression vector consists of cDNA encoding the full-length mouse FGFR-3 IIIb. In these latter two expression vectors, expression of FGFRs was driven by Moloney murine leukemia virus LTR, and expression of neomycin-resistant gene was driven by encephalomyocarditis virus internal ribosomal entry site (EMCV IRES) (Ghattas et al., 1991).

Transfection of the expression vectors to fnr-PC12 cells was performed as described previously (D'Arcangelo and Halegoua, 1993). The transfection was carried out by electroporation, using a Gene Pulser (Bio-Rad, Richmond, CA). Approximately $4 \times 10^{6}$ cells were electroporated in 0.4 $\mathrm{ml}$ of DMEM containing either $20 \mu \mathrm{g}$ of pFlgFL24 plus $2 \mu \mathrm{g}$ of pSV2his (Hartman and Mulligan, 1988) or $20 \mu \mathrm{g}$ of the other expression vectors described above, using settings of $250 \mathrm{~V}$ and $500 \mu \mathrm{F}$. Two days after transfection, cells were incubated in histidine-free RPMI 1640 medium (Life Technologies) containing $1 \mathrm{~mm}$ of histidinol for pFlgFL24transfected cells or $800 \mu \mathrm{g}$ of geneticin (Life Technologies) for the other transfected cells. After $\sim 3$ weeks, histidinol-resistant or neomycinresistant clones were isolated and then screened for aFGF-induced neurite outgrowth and the level of expression of the transfected receptors.

Covalent cross-linking of $\left[{ }^{125}\right.$ I] $a F G F$ to intact cells. Covalent crosslinking of $\left[{ }^{125} \mathrm{I}\right] \mathrm{aFGF}$ to intact cells was performed as described previ- ously (Dionne et al., 1990). Cells were grown on 60-mm-diameter tissue culture dishes coated with human fibronectin (Collaborative Research, Bedford, MA). At $80 \%$ confluency, cells were washed twice with binding buffer (DMEM containing 0.2\% BSA, $5 \mathrm{U} / \mathrm{ml}$ heparin, and $20 \mathrm{~mm}$ HEPES, pH 7.5) and incubated for 90 min on ice with binding buffer containing $25 \mathrm{ng} / \mathrm{ml}\left[{ }^{125} \mathrm{I}\right] \mathrm{aFGF}$. After cells were washed once with binding buffer and once with PBS $(137 \mathrm{~mm} \mathrm{NaCl}, 2.7 \mathrm{mM} \mathrm{KCl}, 4.3 \mathrm{~mm}$ $\mathrm{Na}_{2} \mathrm{HPO}_{4} \cdot 7 \mathrm{H}_{2} \mathrm{O}, 1.4 \mathrm{mM} \mathrm{KH}_{2} \mathrm{PO}_{4}, \mathrm{pH} 7.3$ ), cells were incubated further with PBS containing $0.3 \mathrm{~mm}$ disuccinimidyl suberate (DSS) (Pierce, Rockford, IL) as cross-linker (prepared as $30 \mathrm{~mm}$ stock solution in DMSO). Cells were then washed once with 10 mM HEPES, pH 7.5, 200 mM glycine, 2 mM EDTA, once with PBS, and then scraped in PBS and collected by centrifugation in an Eppendorf centrifuge. Cell pellets were lysed in $50 \mu \mathrm{l}$ of lysis buffer (20 mM HEPES, pH 7.5, $150 \mathrm{~mm} \mathrm{NaCl}, 1 \%$ Triton X-100, $10 \%$ glycerol, $1.5 \mathrm{~mm} \mathrm{MgCl}_{2}, 1 \mathrm{~mm}$ EDTA, $1 \mu \mathrm{g} / \mathrm{ml}$ aprotinin, $1 \mu \mathrm{g} / \mathrm{ml}$ leupeptin, and $1 \mathrm{mM}$ PMSF), incubated for $15 \mathrm{~min}$ on ice, and centrifuged for $15 \mathrm{~min}$ at $4^{\circ} \mathrm{C}$ in an Eppendorf centrifuge. The protein concentrations in the clarified lysates were determined by using BCA protein assay reagent (Pierce). Aliquots of the lysates $(500 \mu \mathrm{g})$ of each sample were mixed with Laemmli sample buffer (Laemmli, 1970), boiled for $4 \mathrm{~min}$, and fractionated on an SDS-7.5\% polyacrylamide gel. The gels were stained with Coomassie brilliant blue to verify that all samples contained equal amounts of protein. Autoradiograms of the dried gels were made on Fuji medical x-ray film RX.

Anti-FGFR antisera. The anti-FGFR-1 antisera flg-2B were raised against the peptide SSGEDSVFSHEPLPEE, the human FGFR-1 C-terminal penultimate sequence. The two different anti-FGFR-2 antisera Bek-78B and Bek-1A were raised against the peptides RPSFSLVEDTTLEPEEPPT (human FGFR-2 N-terminal sequence) and YEPCLPQYPHINGSVKT (human FGFR-2 C-terminal sequence), respectively. These anti-FGFR-1 and anti-FGFR-2 antisera were generously provided by Michael Jaye (Rhône-Poulenc Rorer Central Research). The anti-FGFR-3 monoclonal antibody 8.34 was raised against bacteria-expressed polypeptides encompassing the amino acids $94-255$ of the extracellular domain of human FGFR-3. The anti-FGFR-4 polyclonal antisera were raised against the peptide CGGSPFPFSDSQTT, the C-terminal 11 amino acids of murine FGFR-4 tagged with CGG for conjugation to carrier. These anti-FGFR-4 antisera were generously provided by Jen-Kuei Wang and Mitchell Goldfarb (Regeneron Pharmaceuticals, Tarrytown, NY).

Immunoprecipitation and Western blot. For immunoprecipitation, to detect aFGF-stimulated autophosphorylation of the transfected FGFRs, cells were treated with aFGF for 5 min, lysed in lysis buffer $(20 \mathrm{~mm}$ Tris, $\mathrm{pH}$ 7.6, $150 \mathrm{~mm} \mathrm{NaCl}, 50 \mathrm{~mm} \mathrm{NaF}, 1 \mathrm{~mm} \mathrm{Na} \mathrm{VO}_{4}, 5 \mathrm{~mm}$ benzamidine, 1 mM EDTA, $10 \mu \mathrm{g} / \mathrm{ml}$ leupeptin, $10 \mu \mathrm{g} / \mathrm{ml}$ aprotinin, $1 \mathrm{~mm}$ phenylmethylsulfonyl fluoride, and $1 \%$ Nonidet P-40). The lysates were clarified by the addition of Protein A-Sepharose-4B (Zymed, South San Francisco, CA) and centrifugation. The protein concentrations in the supernatant were determined as described above. Aliquots of the supernatant $(1 \mathrm{mg})$ of each sample were incubated with anti-phosphotyrosine polyclonal antisera SB56 for $1 \mathrm{hr}$ on ice. Protein A-Sepharose-4B was added for an additional $0.5 \mathrm{hr}$. Pellets were collected by centrifugation, washed, boiled in sample buffer, and subjected to SDS-PAGE. Western blotting was performed, and membranes were probed with anti-FGFR-3 antibody.

For Western blotting, (1) to compare the levels of FGFRs in PC12, fnr-PC12, and fnr-PC12-derived transfectant lines, the cells were lysed in lysis buffer and clarified, and the protein concentrations in the lysates were determined. Aliquots of the lysates $(500 \mu \mathrm{g}$ and $75 \mu \mathrm{g}$ for the results shown in Figs. 1 and $6 B$, respectively) of each sample were mixed with sample buffer, boiled, and fractionated on an SDS-7.5\% polyacrylamide gel. Protein was transferred to nitrocellulose membranes (Schleicher \& Schuell, Keene, NH) by electroblotting. Nonspecific binding sites were blocked with blocking buffer (3\% BSA in PBS, $1 \mathrm{~mm}$ EDTA, $1 \mathrm{~mm}$ sodium vanadate) for $1 \mathrm{hr}$ at room temperature. Membranes were then incubated with the appropriate anti-FGFR antiserum diluted in blocking buffer for $1 \mathrm{hr}$ at room temperature. Membranes were washed with PBST (PBS, $0.1 \%$ Tween 20 ) and subsequently incubated with anti-mouse Ig- or anti-rabbit Ig-horseradish peroxidase-linked whole antibody (Amersham, Arlington Heights, IL) at a dilution of 1:2500 in PBS plus 5\% milk, and reactivity was determined by the ECL chemiluminescence reaction (Amersham). (2) To detect aFGF-stimulated tyrosine phosphorylation of total cellular proteins, cells were treated with $50 \mathrm{ng} / \mathrm{ml}$ of aFGF at $37^{\circ} \mathrm{C}$ for the time indicated in the text. Aliquots of the lysates $(75 \mu \mathrm{g})$ of each sample were fractionated on an SDS-7.5\% polyacrylamide gel. Western blotting was performed, and membranes were probed with a solution consisting of 

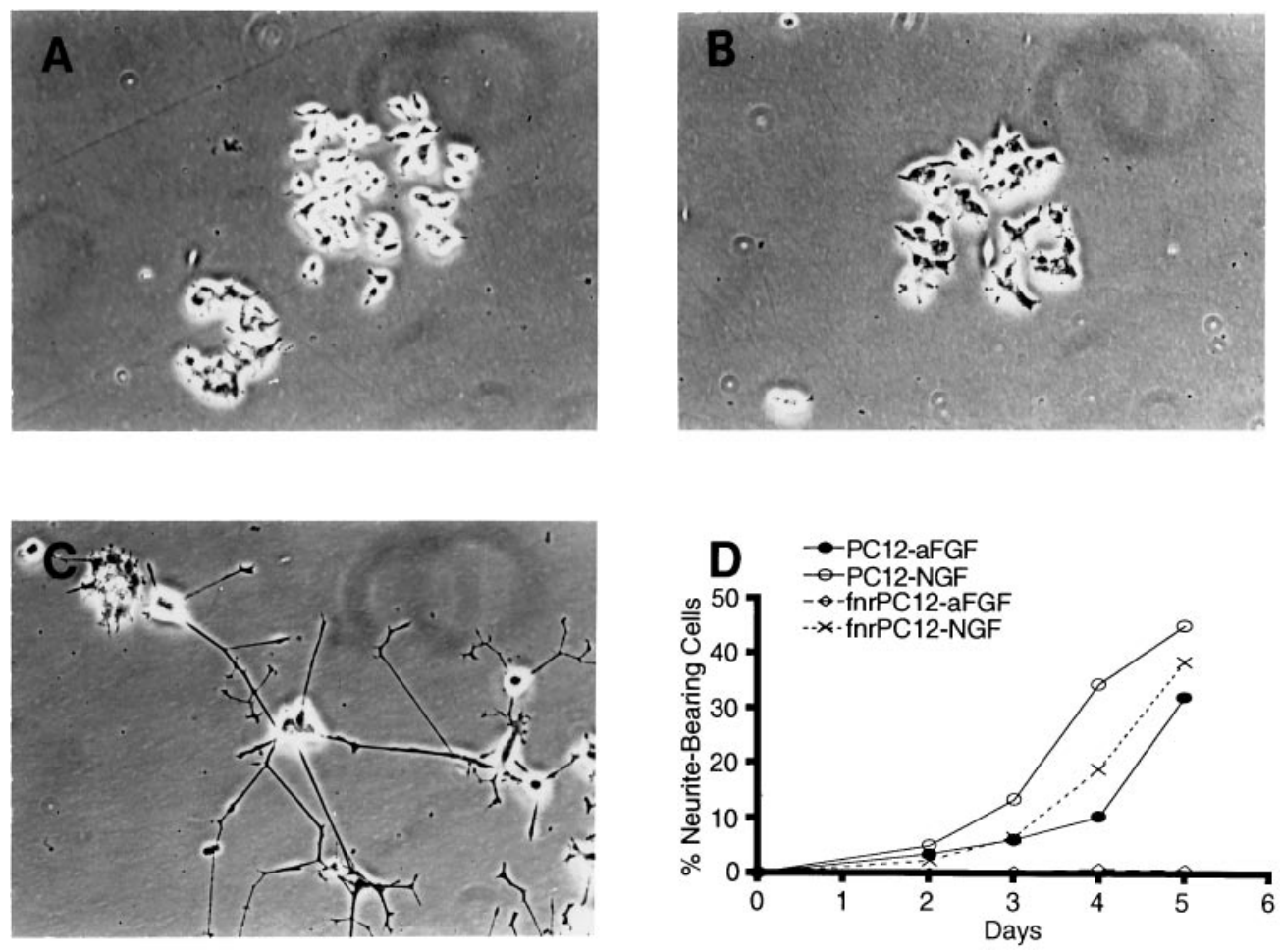

Figure 1. aFGF- and NGF-stimulated neurite outgrowth. PC12 cells and fnrPC12 cells were untreated or treated with $50 \mathrm{ng} / \mathrm{ml} \mathrm{aFGF}$ or $50 \mathrm{ng} / \mathrm{ml} \mathrm{NGF}$. The photographs show the morphology of fnr-PC12 cells, $(A)$ untreated, $(B)$ treated with aFGF, and $(C)$ treated with NGF for $5 \mathrm{~d}(D)$. The percentage of neurite-bearing cells was counted from 2 to $5 \mathrm{~d}$ after treatment with aFGF or NGF.

the anti-phosphotyrosine monoclonal antibody 4G10 (generously provided by Brian J. Druker, Oregon Health Sciences University) at a concentration of $1 \mu \mathrm{g} / \mathrm{ml}$ in blocking buffer. (3) To detect aFGFstimulated activation of MAP kinase, cells were treated with $50 \mathrm{ng} / \mathrm{ml}$ aFGF at $37^{\circ} \mathrm{C}$ for the time indicated in the text. Aliquots of the lysates $(75$ $\mu \mathrm{g}$ ) of each sample were fractionated on an SDS-12.5\% polyacrylamide gel (Leevers and Marshall, 1993). Western blotting was performed, and membranes were probed with a solution consisting of an anti-ERK2 monoclonal antibody (generously provided by Roger Davis, University of Massachusetts, Worcester, MA) in blocking buffer. Activation of MAP kinase was determined by mobility shift. All Western blots were performed in antibody excess.

\section{RESULTS}

\section{Neurite outgrowth of fnr-PC12 cells}

fnr-PC12 cells are a subclone of PC12 cells that show a greatly reduced response in neurite outgrowth after FGF treatment when compared with the parental PC12 cells. For example, when these two cell types were treated with aFGF for $5 \mathrm{~d}$, PC12 cells changed morphology (data not shown) and extended neurites (Fig. 1D), whereas fnr-PC12 cells remained morphologically unchanged (Fig. 1 $A, B)$. In contrast, NGF stimulated neurite outgrowth of both PC12 cells (data not shown) and fnr-PC12 cells (Fig. 1C). When the percentages of neurite-bearing cells were scored, both PC12 cells and fnr-PC12 cells showed a similar level of response to NGF (Fig. 1D). These results indicate that fnr-PC12 cells are defective in some aspect of the FGF-specific signaling pathway.

\section{Chemical cross-linking of $\left[{ }^{125}\right.$ I]aFGF to fnr-PC12 cells}

To examine whether the FGF-nonresponsiveness of the fnr-PC12 cells was attributable to a lack of cell surface receptors, we determined the level of aFGF binding sites on PC12 and fnr-PC12 cells by chemical cross-linking of $\left[{ }^{125} \mathrm{I}\right] \mathrm{aFGF}$. In PC12 cells, a major band of $180 \mathrm{kDa}$ was cross-linked to $\left[{ }^{125} \mathrm{I}\right] \mathrm{aFGF}$. This band, however, was barely seen in fnr-PC12 cells (Fig. $2 A$ ). With a longer exposure of the gel, two bands of 180 and $160 \mathrm{kDa}$ were found to be cross-linked to $\left[{ }^{125} \mathrm{I}\right] \mathrm{aFGF}$ in both cells. The relative intensity of these two bands was different in these two cells. In PC12 cells, the band of $180 \mathrm{kDa}$ was much stronger than the band of $160 \mathrm{kDa}$. In fnr-PC12 cells, however, the band of $160 \mathrm{kDa}$ was slightly stronger than the band of $180 \mathrm{kDa}$ (Fig. 2B). These results indicate that fnr-PC12 cells have endogenous FGF receptors, but at a significantly reduced level in comparison with PC12 cells.

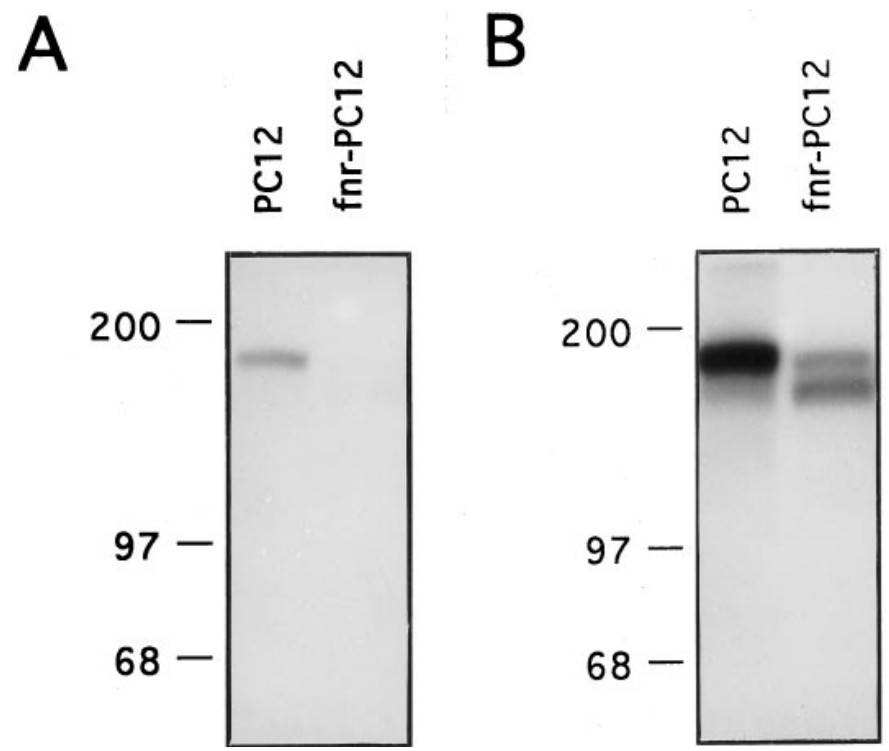

Figure 2. Cross-linking of $\left[{ }^{125} \mathrm{I}\right] \mathrm{aFGF}$ to $\mathrm{PC} 12$ and fnr-PC12 cells. PC12 cells or fnr-PC12 cells were incubated with $25 \mathrm{ng} / \mathrm{ml}\left[{ }^{125} \mathrm{I}\right] \mathrm{aFGF}$ for $90 \mathrm{~min}$, followed by cross-linking with DSS. The lysates were fractionated by SDS-PAGE, and the gel was exposed for autoradiography. $A$, Four day exposure of the gel; $B, 33 \mathrm{~d}$ exposure of the gel. 
Figure 3. Analysis of expression of FGFRs in PC12 and fnr-PC12 cells. The cells were lysed in lysis buffer, fractionated by SDS-PAGE, and transferred to nitrocellulose membrane. The blots were probed with anti-FGFR-1, antiFGFR-3, or anti-FGFR-4 antibodies as indicated in the figure. These antibodies recognize immature and mature forms of the receptors in addition to some unknown proteins. For the sake of clarity, we have indicated the position of the mature forms of the receptors with arrowheads.

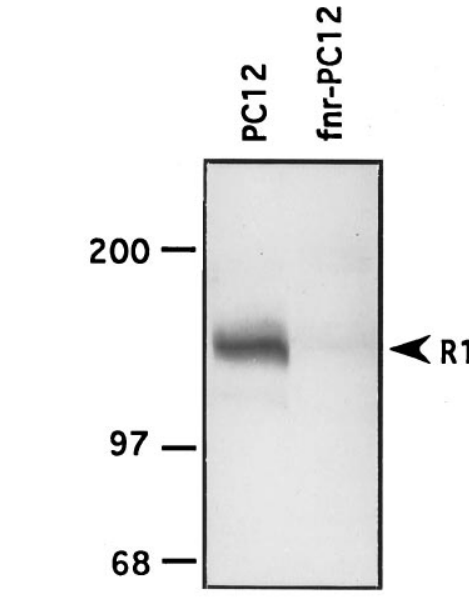

Blots: anti-FGFR-1

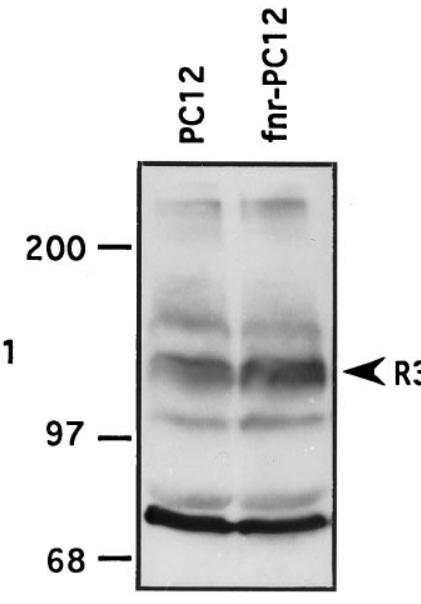

anti-FGFR-3

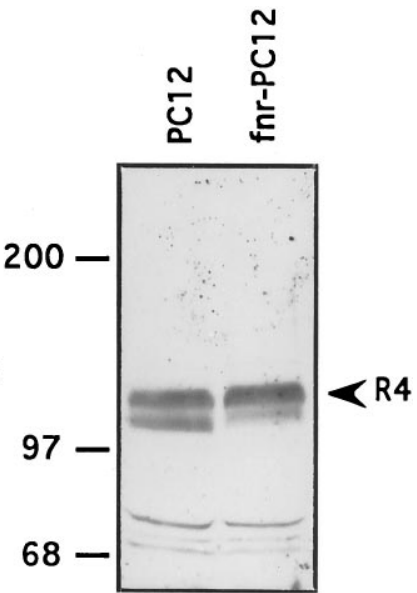

anti-FGFR-4
Analysis of FGF receptors expressed in PC12 cells and fnr-PC12 cells

To determine which specific FGF receptor was no longer expressed at high level in fnr-PC12 cells, the expression of the four known FGF receptors was analyzed by Western blot probing with receptor-specific antibodies (Fig. 3). The endogenous level of FGFR-1 was found to be much lower in fnr-PC12 cells when compared with PC12 cells, whereas the endogenous level of FGFR-3 or -4 essentially remained the same. By using two different anti-FGFR-2 antibodies for this analysis, we failed to detect the expression of FGFR-2 in these cells (data not shown). On the basis of the known molecular weights of FGFR-1, -3 and -4 , together with these expression studies, this would indicate that the $180 \mathrm{kDa}$ receptor detected by ligand binding in Figure $2 \mathrm{~B}$ is FGFR-1 and the $160 \mathrm{kDa}$ receptor is FGFR-3. No ligand-binding activity was detected, even on the longer exposures, that would correspond to FGFR-4. Furthermore, these results also suggest that the endogenous FGFR-3 and -4 are unable to induce neurite outgrowth and that the reduced expression of FGFR-1 may be responsible for the inability of fnr-PC12 cells to undergo efficient aFGF-induced neurite outgrowth.

\section{Transfection of fnr-PC12 cells with FGFR-1 or -3 restores aFGF-stimulated neurite outgrowth of fnr-PC12 cells with different efficiency}

Western blot analysis of endogenous FGF receptors in PC12 cells and fnr-PC12 cells revealed that fnr-PC12 cells expressed greatly reduced levels of FGFR-1 but essentially the same levels of FGFR-3 and -4 (Fig. 3). We hypothesized that if this reduced level of FGFR-1 expression caused the lack of neurite outgrowth, then transfection of FGFR-1 into these cells should restore aFGFstimulated neurite outgrowth. Because the functional role of different FGFRs in PC12 cells was not known and at least three different FGFRs were coexpressed in these cells, it was also possible that transfection of any of the three receptors into fnrPC12 cells and selection of high-level expressors would also restore FGF-induced neurite outgrowth in these cells. To address these hypotheses, human FGFR-1 or -3 cDNA was transfected into fnr-PC12 cells. Cell lines stably expressing FGFR-1 or -3 were selected and screened by aFGF-stimulated neurite outgrowth and cross-linking of the cells with $\left[{ }^{125} \mathrm{I}\right] \mathrm{aFGF}$. Among the 20 FGFR1-transfected clones and 20 FGFR-3-transfected clones tested, FGFR-1-transfected clones elaborated neurites more efficiently than FGFR-3-transfected clones when treated with aFGF. This result indicates that FGFR-1 and -3 may have different potentials to restore aFGF-stimulated neurite outgrowth in fnr-PC12 cells. To compare quantitatively the functional difference between these two receptors, the percentage of neurite-bearing cells was scored for clones expressing approximately equal levels of transfected FGFR-1 or -3. Analysis of one clone of FGFR-1, hR1-3B2, and two clones of FGFR-3 expressors, hR3-1D1 and hR3-1D2, demonstrates the different efficiency of aFGF-stimulated neurite outgrowth by these two receptors (Fig. 4). As determined by crosslinking of $\left[{ }^{125} \mathrm{I}\right] \mathrm{aFGF}$ to these cells, all of these three transfected clones showed increased levels of cell surface aFGF binding sites when compared with the parental line fnr-PC12 cells (Fig. $4 A$ ). Among these clones, hR3-1D2 and hR1-3B2 expressed equally high levels of transfected receptors (Fig. $4 A$ ), yet the efficiency of aFGF-induced neurite outgrowth was dramatically different (Fig. $4 B)$. After the $5 \mathrm{~d}$ treatment with aFGF, the percentage of neurite-bearing cells in hR1-3B2 cells was significantly higher than that in PC12 cells, whereas the percentage of neurite-bearing cells in hR3-1D2 was significantly lower than that in PC12 cells or hR1-3B2 cells. Therefore, expression of human FGFR-1 to a high level in fnr-PC12 cells efficiently restored aFGF-induced neurite outgrowth, and expression of human FGFR-3 in these cells did not. These results indicate that FGFR-1 and -3 may have different potentials to induce neurite outgrowth in PC12 cells.

To rule out the possibility that the difference between these two receptors reflected differences in their abilities to bind to aFGF, cDNAs encoding either the full-length mouse FGFR-3 or a chimeric receptor, FR31b, with the extracellular domain of mouse FGFR-3 fused to the transmembrane domain and intracellular domain of FGFR-1 (Fig. 5) were transfected into fnr-PC12 cells. Fnr-PC12 cells transfected with either the mouse FGFR-3 or the chimeric receptor were selected for neo-resistance and screened for aFGF-stimulated neurite outgrowth and by Western blot analysis for receptor expression. At least 95 clones of each receptortransfected cell were tested for their response to aFGF. Among the FR31b-transfected clones, $19 \%$ of the clones showed outgrowth of long and dense neurites after only an overnight incubation of the cells with aFGF, whereas no significant level of neurites was found in any of the mouse FGFR-3-transfected clones (data not shown). The Western blot analysis indicated that the FR31b clones that elaborated neurites when aFGF was added 
A

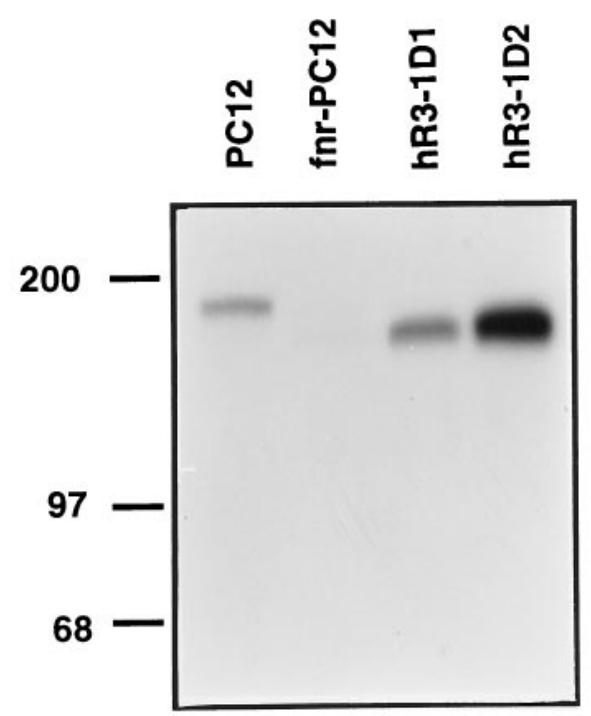

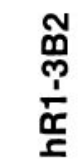

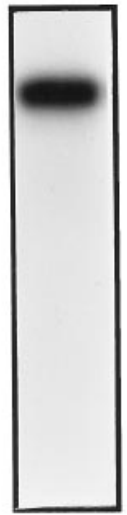

B

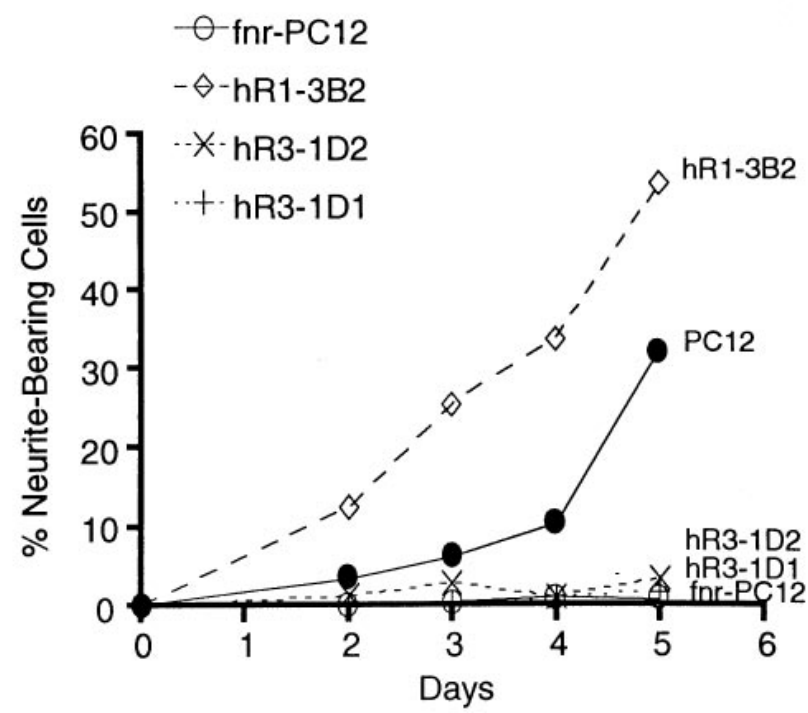

Figure 4. Overexpression of human FGFR-1, but not FGFR-3, in fnr-PC12 cells restored aFGF-induced neurite outgrowth. $A$, Cross-linking of PC12 cells, fnr-PC12 cells, FGFR-3-expressing clones hR3-1D1 and hR3-1D2, and FGFR-1-expressing clone hR1-3B2 with [ $\left.{ }^{125} \mathrm{I}\right] \mathrm{aFGF}$. $B$, Score of percentage of neurite-bearing cells for aFGF-treated PC12 cells, fnr-PC12 cells, FGFR-1-expressing clone hR1-3B2, and FGFR-3-expressing clones hR3-1D1 and hR3-1D2.

were those that expressed the FR31b receptor. In contrast, although none of the FGFR-3 transfected clones efficiently elaborated neurites, several clones were identified that expressed high levels of FGFR-3. This indicates that the transmembrane domain and intracellular domain of FGFR-1 is sufficient to confer the high efficiency of induction of neurite outgrowth to fnr-PC12 cells. To quantitatively compare the difference between FR31b and FGFR-3, we identified several clones expressing equivalent levels of transfected FR31b or FGFR-3 and compared them for the percentage of neurite-bearing cells when aFGF was added. Representative data from two such clones is shown in Figure 6. Comparison of an FR31b-transfected clone, FR31b-1D1, and an FGFR3-transfected clone, FR3IIIb-1C4, clearly demonstrates the difference in the efficiency of aFGF-stimulated neurite outgrowth by these two receptors (Fig. 6). As determined by Western blot analysis using an antibody against the extracellular domain, the

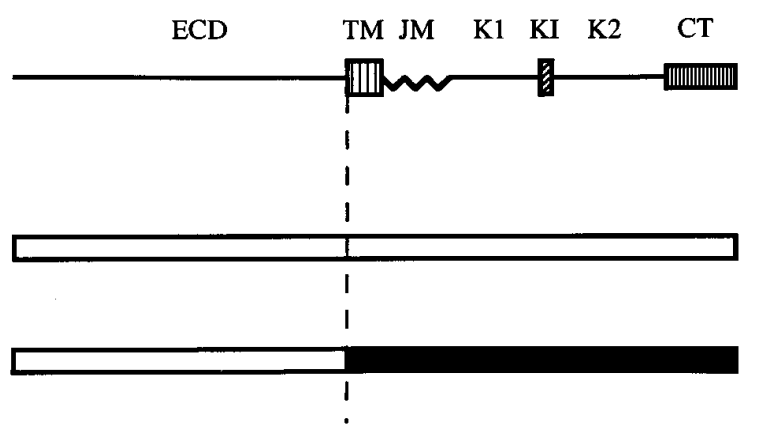

FR3IIIb

FR3Ib

Figure 5. Construction of mouse FGFR-3/FGFR-1 chimera. FR3IIIb represents the full-length mouse FGFR-3IIIb form. cDNA encoding this receptor was inserted in an expression vector containing Moloney murine leukemia virus LTR, EMCV IRES, neomycin-resistant gene, SV40 polyadenylation sequence, and pBS-SK sequence. FR31b represents a chimeric receptor with mouse FGFR-3IIIb extracellular domain sequences fused to mouse FGFR-1 sequences from the transmembrane domain to the $\mathrm{C}$ terminus. cDNA encoding this chimeric receptor was inserted in an expression vector as described for the construct of FR3IIIb. level of expression of mouse FGFR-3 in FR3IIIb-1C4 was slightly higher than the level of FR31b in FR31b-1D1 (Fig. 6 $A$ ). The efficiency of aFGF-stimulated neurite outgrowth of FR3IIIb-1C4, however, was lower than the efficiency of FR31b-1D1 (Fig. 6B). When the cells were incubated with aFGF for more than $2 \mathrm{~d}$, FR3IIIb-1C4 cells had significant neurite outgrowth, yet the neurites were less dense and shorter than the neurites of FR31b-1D1 (data not shown). The higher efficiency of neurite outgrowth in FR3IIIb-1C4 (Fig. 6B) compared with the poor efficiency in hR3-1D2 (Fig. 4B) could be attributed to the higher level of receptor expression in FR3IIIb-1C4 cells or species-specific difference. During the course of this analysis, we have analyzed $>100$ individual clones expressing various FGFR constructs. We have noticed that FGFR-1, or FR31b clones, expressing high levels of receptor respond very quickly to aFGF addition, whereas those expressing intermediate levels respond more slowly, and the clones with low level expression respond the slowest to aFGF addition. This observation indicates that the expression level of the receptor is an important factor in determining the responsiveness of the cells to aFGF. Cells expressing very high levels of FGFR-3, however, still respond only poorly to aFGF addition. In summary, the results with the chimeric receptor FR31b further support the notion that FGFR-1 has a significantly higher potential than FGFR-3 to induce neurite outgrowth.

\section{Comparison of signaling potentials of the FR31b chimera and FGFR-3 in fnr-PC12 cells}

It is likely that differences in the signaling potential of FGFR-1 and -3 may be responsible for the differences in the efficiency of induction of neurite outgrowth. To dissect the molecular signaling events required for efficient induction of neurite outgrowth, fnrPC12, FR31b-1D1, and FR3IIIb-1C4 cells were treated with aFGF for different time periods, and the aFGF-stimulated increase in tyrosine phosphorylation was analyzed. After stimulation with aFGF for 2-60 min, both FR31b-1D1 and FR3IIIb-1C4 cells showed an increase in tyrosine phosphorylation of a similar array of proteins (Fig. $7 A$ ). The most prominent increase in 
A

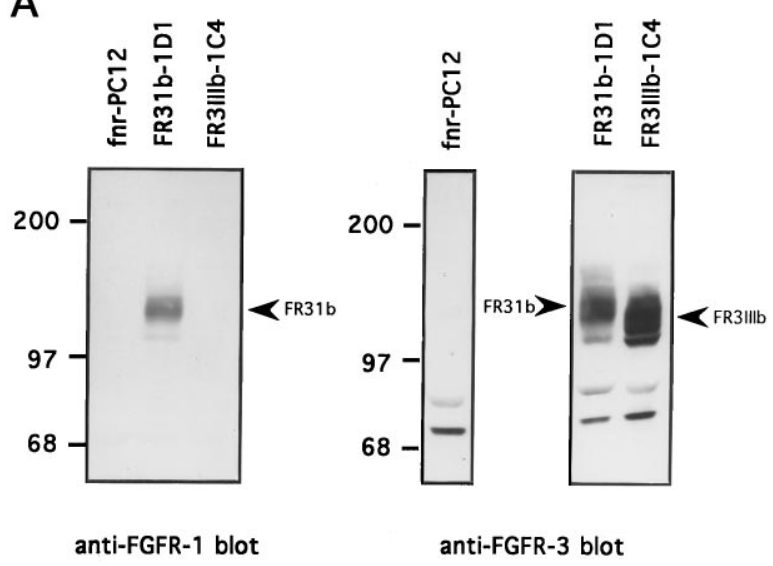

B

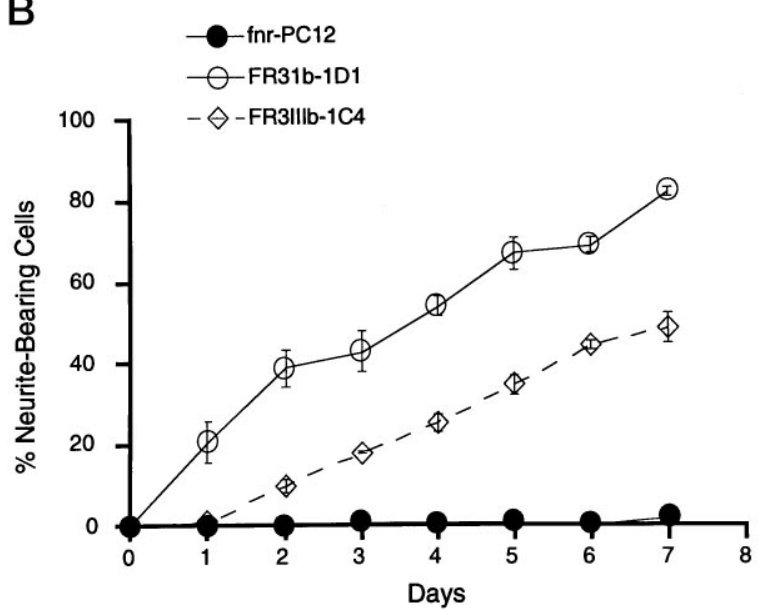

Figure 6. FR31b has higher potential to induce neurite outgrowth than FGFR3. $A$, Western blot analysis of expression of FGFRs in FR31b-1D1 cells and FR3IIIb-1C4 cells. $B$, Score of the percentage of neurite-bearing cells of aFGF-treated fnr-PC12 cells, FR31b-1D1, and FR3IIIb-1C4 cells from 0 to $7 \mathrm{~d}$ after treatment with aFGF.

tyrosine phosphorylation seen in FR31b-1D1 cells was in a $90 \mathrm{kDa}$ protein (Fig. $7 A$ ). The signal was seen within 2 min and persisted for 60 min, whereas in FR3IIIb-1C4 cells, the signal was not as strong as seen in FR31b-1D1 cells and was already maximum at 2 $\mathrm{min}$ and proceeded to decrease. Interestingly, the decline seemed to be maximal after $30 \mathrm{~min}$, and then there was a slight increase in the phosphorylation of several proteins at the $60 \mathrm{~min}$ time point. This is most easily seen for the two proteins of apparent molecular weights 44,000 and 42,000, Figure $7 A$. The reason for this transient decline is unknown, but it is a reproducible phenomenon, having been seen in six separate experiments. In addition to the $90 \mathrm{kDa}$ protein, several other proteins seemed to be phosphorylated to higher levels after FR31b activation than they were after FGFR-3 activation. Results similar to those obtained with FR31b were seen when FGFR-1 was used (data not shown). It is also interesting to note that certain proteins were phosphorylated more significantly after FGFR-3 activation than after FR31b activation. For example, see those at 42 and $35 \mathrm{kDa}$ (Fig. $7 A$ ). This indicates that it is not just that FGFR-3 activation is somehow weaker than FR31b activation; Figure $7 B$ shows that both receptors were autophosphorylated in response to aFGF stimulation. Higher basal levels of FGFR-3 autophosphorylation without aFGF treatment of the cells were observed reproducibly. The reason for this is unknown. These data indicate that in general, FR31b and FGFR-1 may phosphorylate and activate the key component for neurite outgrowth more efficiently than FGFR-3.

\section{Kinetics of MAP kinase phosphorylation by FR31b and FGFR-3}

Previous studies have indicated that activation of MAP kinase is involved in neurite outgrowth. Furthermore, for efficient neurite outgrowth, the activation of MAP kinase has to be persistent. Therefore we examined the abilities of both FR31b and FGFR-3 to activate MAP kinase. Activation of MAP kinase has been shown to result in a reduced mobility of the MAP kinase protein in SDSPAGE. We examined aFGF-stimulated activation of MAP kinase by FR31b or FGFR-3 using this assay (Fig. 8). The parental line fnrPC12 still contains some endogenous FGF receptors, and addition of aFGF to these cells showed a small but detectable activation of MAP kinase that was maximum at $5 \mathrm{~min}$ and transient in nature. Overexpression of FR31b or FGFR-3 greatly enhanced MAP kinase activation, but the activation is more prolonged in cells expressing FR31b; again similar results were obtained with FGFR-1 (data not shown). At least $50 \%$ of the activated form of the enzyme was still present after 60 min of treatment, whereas the signal by FGFR-3 was much more transient compared to the signal by FR31b. Within the first 5 min, the levels of activation by FR31b and FGFR-3 were similar; however, by 10 min the MAP kinase was returning to its inactive form in FGFR-3-expressing cells, whereas a significant portion of the enzyme was still active in FR31b-expressing cells (Fig. 8). On the basis of previous studies, this difference in the ability to induce prolonged activation of MAP kinase may be sufficient to explain the differing abilities of these two FGF receptors to induce neurite outgrowth.

\section{DISCUSSION}

Analysis of an FGF-nonresponsive PC12 subclone, named fnr$\mathrm{PC} 12$, has allowed us to determine the role of the different FGFRs in FGF-stimulated neurite outgrowth. By cross-linking with $\left.{ }^{125} \mathrm{I}\right] \mathrm{aFGF}$, these cells expressed a greatly reduced level of FGFRs when compared with the level in PC12 cells. By Western blot analysis, the major difference of endogenous FGFRs was the greatly reduced level of FGFR-1 in fnr-PC12 cells. Previous studies by overexpression of some other growth factor receptors, such as EGF receptor (Traverse et al., 1994), insulin receptor (Dikic et al., 1994), or PDGF receptor (Heasley and Johnson, 1992), or selection of PC12 variants expressing reduced levels of NGF receptor (Schlessinger and Bar-Sagi, 1994), suggest that the number of receptors affects the biological outcome: differentiation versus mitogenesis. Ligand activation of PC12 cells that highly overexpressed any of these receptor tyrosine kinases led to sustained activation of MAP kinase, cessation of cell division, and stimulated neurite outgrowth. In contrast, PC12 cells that expressed these receptors below a threshold level no longer stimulated neurite outgrowth. These experiments raised two possibilities for the defect in neurite outgrowth seen in fnr-PC12 cells. One possibility is that the number of endogenous FGFRs is not high enough to give rise to FGF-stimulated neurite outgrowth. If the different FGFRs in PC12 cells are functionally redundant, transfection of any FGFR should restore FGF-stimulated neurite outgrowth with the same efficiency. The other possibility is that fnr-PC12 cells lack the receptor that is mainly responsible for neurite outgrowth. Our results support this second possibility. 
A

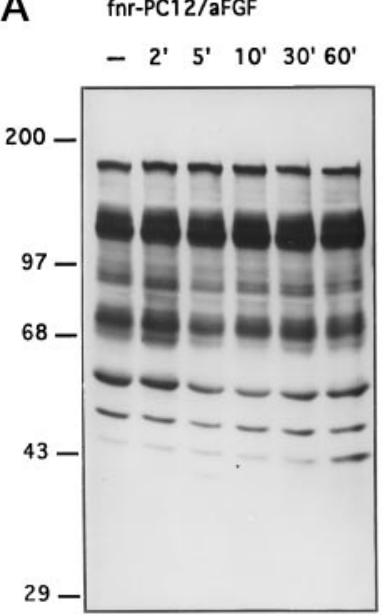

FR31b-1D1/aFGF
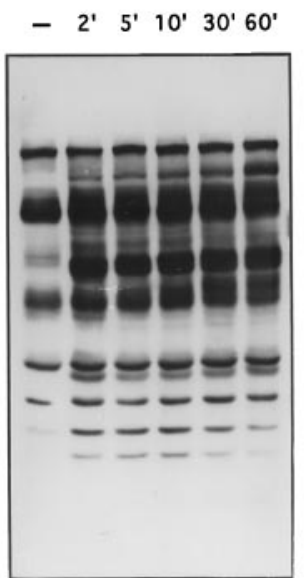

FR3IIIb-1C4/aFGF

- 2' 5' $10^{\prime} 30^{\prime} 60^{\prime}$

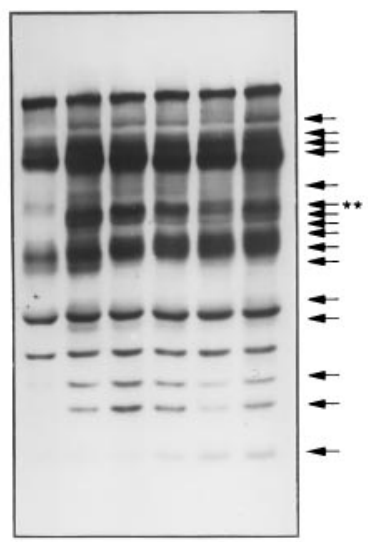

B

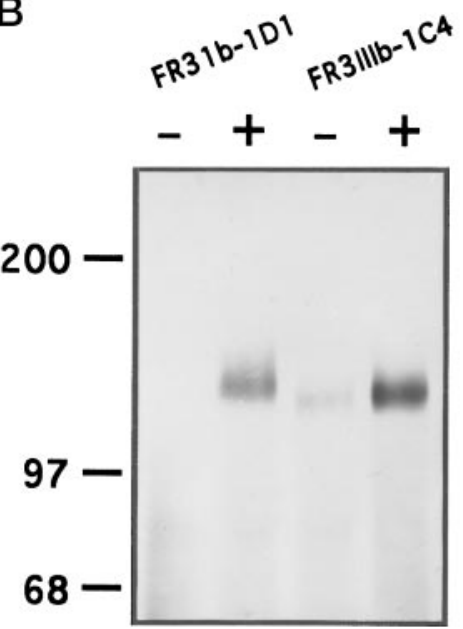

Figure 7. Activation of FGFR-1 kinase in FR31b-transfected fnr-PC12 cells induces stronger and more persistent protein tyrosine phosphorylation than activation of FGFR-3 kinase in FR3IIIb-transfected fnr-PC12 cells. Fnr-PC12 cells, FR31b-1D1 cells, and FR3IIIb-1C4 cells were untreated or treated with aFGF for 2, 5, 10,30, or $60 \mathrm{~min}$. The cells were lysed and subjected to SDS-PAGE. $A$, The increase in tyrosine phosphorylation of cellular substrates was monitored with an anti-phosphotyrosine antibody, 4G10. Proteins phosphorylated on addition of aFGF are indicated by arrowheads. The position of the $90 \mathrm{kDa}$ protein discussed in the text is indicated by double asterisks. B, IP: anti-phosphotyrosine; blot: anti-FGFR-3. Autophosphorylation of the receptor molecules was assayed by immunoprecipitation of the lysates with an anti-phosphotyrosine antibody, SB56, followed by Western blotting and probing with the anti-human FGFR-3 monoclonal antibody.

FGFR-1 was significantly more active than FGFR-3 in the induction of neurite outgrowth when both receptors are overexpressed at high level. This suggests that these two receptors are not functionally redundant for induction of neurite outgrowth in PC12 cells. Even though overexpression of FGFR-3 in fnr-PC12 cells may restore some aFGF-stimulated neurite outgrowth in these cells, this may not represent the physiological role of FGFR-3 in PC12 cells, because in the absence of FGFR-1 the physiological level of FGFR-3 and -4 found in fnr-PC12 cells cannot support aFGF-stimulated neurite outgrowth. Therefore, FGFR-1 seems to be the FGFR primarily responsible for induction of neurite outgrowth. Additional experiments will be necessary to explore the role of the other FGFRs in the differentiation of PC12 cells.

Recent reports suggest that activation of multiple signal transduction pathways and the duration of activation are essential for growth factor-stimulated neurite outgrowth in PC12 cells (Peng et al., 1995; Vaillancourt et al., 1995). In this study, we demonstrate that neurite outgrowth correlates with the differing ability of the different FGF receptors to activate MAP kinase. FGFR-1 acti- vates MAP kinase in a more sustained manner than FGFR-3. This is consistent with previous observations for other growth factor receptors expressed in PC12 cells. In these studies, it was demonstrated that sustained activation of MAP kinase correlates with efficient induction of neurite outgrowth (Heasley and Johnson, 1992; Hempstead et al., 1992; Dikic et al., 1994; Traverse et al., 1994). In addition to MAP kinase, the higher phosphorylation of an array of cellular proteins that is induced by FGFR-1 (Fig. 6A) may also play a role in the more efficient induction of neurite outgrowth by this receptor. Among these proteins, the higher and more sustained phosphorylation of the $90 \mathrm{kDa}$ protein (Fig. 6A) and Shc (H. Lin and M. Hayman, unpublished data) further suggests that FGFR-1 activates ras signaling pathway more efficiently than FGFR-3 (Klint et al., 1995). Activation of the proteins PLC $\gamma$, Src, and SNT has been implicated in the signaling pathway for neurite outgrowth in PC12 cells (Peng et al., 1995; Vaillancourt et al., 1995). Whether these two receptors differentially activate other signaling pathways involving these molecules remains to be determined. Interestingly, in other cell types both
fnr-PC12/aFGF

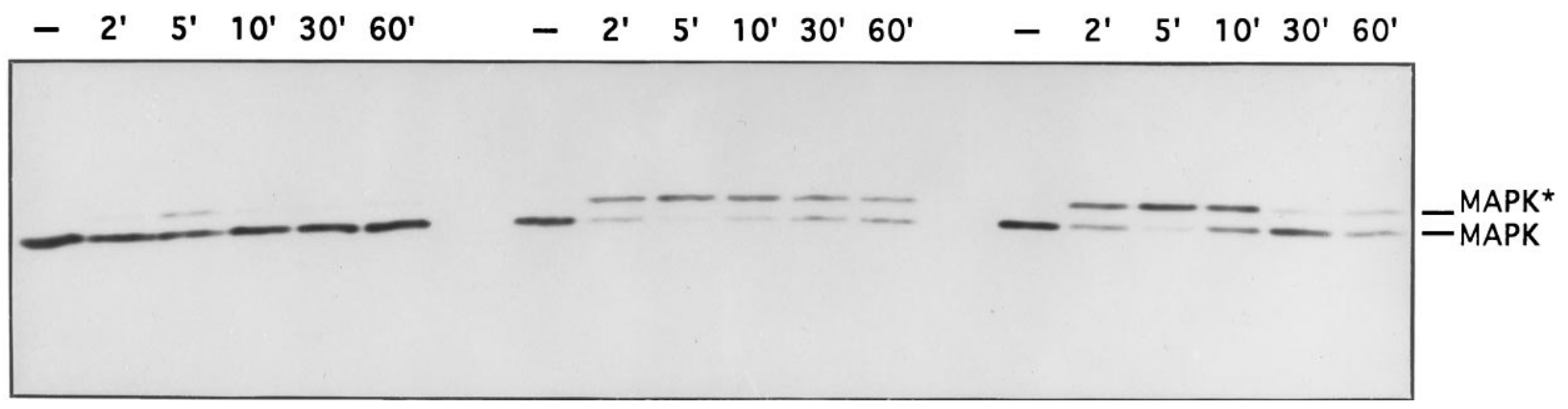

Figure 8. Kinetics of aFGF-induced activation of MAP kinase in fnr-PC12, FR31b-1D1, and FR3IIIb-1C4 cells. The cells were untreated or treated with aFGF for 2, 5, 10, 30, or $60 \mathrm{~min}$. The lysates were subjected to SDS-PAGE followed by Western blotting using an anti-ERK2 antibody. The activation of MAP kinase was detected by mobility shift in the SDS-PAGE. MAPK, Inactive form of MAP kinase; MAPK*, activated form of MAP kinase. 
FGFR-3 and -4 have weaker functional potentials when compared with FGFR-1 (Ornitz and Leder, 1992; Wang et al., 1994; Shaoul et al., 1995). The underlying mechanism for this weaker potential remains unclear.

FGFR-1, -2 , and -3 are distributed differentially throughout the nervous system among various neuronal as well as glial cell types (Heuer et al., 1990; Wanaka et al., 1990; Thompson et al., 1991; Asai et al., 1993; Peters et al., 1993; Yazaki et al., 1994). These distributions suggest that the FGFRs have diverse functions and that each receptor may regulate unique phenotypic characteristics of neuronal and glial cells. Our data support these ideas in that two different FGF receptors have been shown to confer different functionalities in the same neuronal background. FGFR-1 is much more effective in regulating characteristics associated with neurite outgrowth than is FGFR-3. This may be consistent with the more prevalent distribution of FGFR-1 in neuronal cell types (Heuer et al., 1990; Wanaka et al., 1990; Thompson et al., 1991; Asai et al., 1993; Peters et al., 1993; Yazaki et al., 1994). Because FGFR-3 is found in some neuronal cell types, and occasionally in cells with overlapping FGFR-1 expression, it will be of interest to determine whether any neuronal phenotypes other than neurite outgrowth may be elicited through FGFR-3.

\section{REFERENCES}

Anderson KJ, Dam D, Lee S, Cotman CW (1988) Basic fibroblast growth factor prevents death of lesioned cholinergic neurons in vivo. Nature 332:360-361.

Asai T, Wanaka A, Kato H, Masana Y, Seo M, Tohyama M (1993) Differential expression of two members of FGF receptor gene family, FGFR-1 and FGFR-2 mRNA, in the adult rat central nervous system. Mol Brain Res 17:174-178.

Baird A (1994) Fibroblast growth factors: activities and significance of non-neurotrophin neurotrophic growth factors. Curr Opin Neurobiol 4:78-86.

Basilico C, Moscatelli D (1992) The FGF family of growth factors and oncogenes. Adv Cancer Res 59:115-165.

Birren SJ, Anderson DJ (1990) A v-myc-immortalized sympathoadrenal progenitor cell line in which neuronal differentiation is initiated by FGF but not by NGF. Neuron 4:189-201.

Chellaiah AT, McEwen DG, Werner S, Xu J, Ornitz DM (1994) Fibroblast growth factor receptor (FGFR) 3. Alternative splicing in immunoglobulin-like domain III creates a receptor highly specific for acidic FGF/FGF-1. J Biol Chem 269:11620-11627.

Claude P, Parada IM, Gordon KA, D'Amore PA, Wagner JA (1988) Acidic fibroblast growth factor stimulates adrenal chromaffin cells to proliferate and to extend neurites, but is not a long-term survival factor. Neuron 1:783-790.

Cordeiro PG, Seckel BR, Lipton SA, D'Amore PA, Wagner J, Madison R (1989) Acidic fibroblast growth factor enhances peripheral nerve regeneration in vivo. Plast Reconstr Surg 83:1013-1019.

D'Arcangelo G, Halegoua S (1993) A branched signaling pathway for nerve growth factor is revealed by src-, ras-, and raf-mediated gene inductions. Mol Cell Biol 13:3146-3155.

Dikic I, Schlessinger J, Lax I (1994) PC12 cells overexpressing the insulin receptor undergo insulin-dependent neuronal differentiation. Curr Biol 4:702-708.

Dionne CA, Crumley G, Bellot F, Kaplow JM, Searfoss G, Ruta M, Burgess WH, Jaye M, Schlessinger J (1990) Cloning and expression of two distinct high-affinity receptors cross-reacting with acidic and basic fibroblast growth factors. EMBO J 9:2685-2692.

Eckenstein FP (1994) Fibroblast growth factors in the nervous system. J Neurobiol 25:1467-1480.

Eckenstein FP, Esch F, Holbert T, Blacher RW, Nishi R (1990) Purification and characterization of a trophic factor for embryonic peripheral neurons: comparison with fibroblast growth factors. Neuron 4:623-631.

Engele J, Bohn MC (1991) The neurotrophic effect of fibroblast growth factors on dopaminergic neurons in vitro are mediated by mesencephalic glia. J Neurosci 11:3070-3078.
Ghattas IR, Sanes JR, Majors JE (1991) The encephalomyocarditis virus internal ribosome entry site allows efficient coexpression of two genes from a recombinant provirus in cultured cells and in embryos. Mol Cell Biol 11:5848-5859.

Ghosh A, Greenberg ME (1995) Distinct roles for bFGF and NT-3 in the regulation of cortical neurogenesis. Neuron 15:89-103.

Greene LA, Tischler AS (1976) Establishment of a noradrenergic clonal line of rat adrenal pheochromocytoma cells which respond to nerve growth factor. Proc Natl Acad Sci USA 73:2424-2428.

Greene LA, Tischler AS (1982) PC12 pheochromocytoma cultures in neurobiological research. Adv Cell Neurobiol 3:373-414.

Hartman SC, Mulligan RC (1988) Two dominant-acting selectable markers for gene transfer studies in mammalian cells. Proc Natl Acad Sci USA 85:8047-8051.

Heasley LE, Johnson GL (1992) The beta-PDGF receptor induces neuronal differentiation of PC12 cells. Mol Biol Cell 3:545-553.

Hempstead BL, Rabin SJ, Kaplan L, Reid S, Parada LF, Kaplan DR (1992) Overexpression of the trk tyrosine kinase accelerates nerve growth factor-induced differentiation. Neuron 9:883-896.

Heuer JG, von Bartheld CS, Kinoshita Y, Evers PC, Bothwell M (1990) Alternating phases of FGF receptor and NGF receptor expression in the developing chicken nervous system. Neuron 5:283-296.

Jaye M, Lyall RM, Mudd R, Schlessinger J, Sarver N (1988) Expression of acidic fibroblast growth factor cDNA confers growth advantage and tumorigenesis to Swiss 3T3 cells. EMBO J 7:963-969.

Jaye M, Schlessinger J, Dionne CA (1992) Fibroblast growth factor receptor tyrosine kinases: molecular analysis and signal transduction. Biochim Biophys Acta 948:327-344.

Johnson DE, Williams LT (1993) Structural and functional diversity in the FGF receptor multigene family. Adv Cancer Res 60:1-41.

Keegan K, Johnson DE, Williams LT, Hayman MJ (1991) Isolation of an additional member of the fibroblast growth factor receptor family, FGFR-3. Proc Natl Acad Sci USA 88:1095-1099.

Klint P, Kanda S, Claesson-Welsh L (1995) Shc and a novel $89 \mathrm{kDa}$ component couple to the Grb2-Sos complex in fibroblast growth factor2-stimulated cells. J Biol Chem 270:23337-23344.

Kremer NE, D'Arcangelo G, Thomas SM, DeMarco M, Brugge JS, Halegoua S (1991) Signal transduction by nerve growth factor and fibroblast growth factor in PC12 cells requires a sequence of src and ras actions. J Cell Biol 115:809-819.

Laemmli UK (1970) Cleavage of structural proteins during the assembly of the head of bacteriophage T4. Nature 227:680-685.

Leevers SJ, Marshall CJ (1993) Activation of extracellular signalregulated kinase, by p21ras oncoprotein. EMBO J 11:569-574.

Lipton SA, Wagner JA, Madison RD, D'Amore PA (1988) Acidic fibroblast growth factor enhances regeneration of processes by postnatal mammalian retinal ganglion cells in culture. Proc Natl Acad Sci USA 85:2388-2392.

MacMillan V, Judge D, Wiseman A, Settles D, Swain J, Davis J (1993a) Mice expressing a bovine basic fibroblast growth factor transgene in the brain show increased resistance to hypoxemic-ischemic cerebral damage. Stroke 24:1735-1739.

MacMillan V, Walton RK, Davis J (1993b) Acidic fibroblast growth factor infusion reduces ischemic CA1 hippocampal damage in the gerbil. Can J Neurosci 20:37-40.

Mason IJ (1994) The ins and outs of fibroblast growth factors. Cell 78:547-552.

Miller AD, Rosman GJ (1989) Improved retroviral vectors for gene transfer and expression. Biotechniques 7:980-990.

Mobley WC, Schenker A, Shooter EM (1976) Characterization and isolation of proteolytically modified nerve growth factor. Biochemistry 15:5543-5552.

Morrison RS, Sharma A, DeVellis J, Bradshaw RA (1986) Basic fibroblast growth factor supports the survival of cerebral cortical neurons in primary culture. Proc Natl Acad Sci USA 83:7535-7541.

Nakata N, Kato H, Kogure K (1993) Protective effects of basic fibroblast growth factor against hippocampal neuronal damage following cerebral ischemia in the gerbil. Brain Res 605:354-356.

Ornitz DM, Leder P (1992) Ligand specificity and heparin dependence of fibroblast growth factor receptors 1 and 3. J Biol Chem 267:16305-16311.

Partanen J, Vainikka S, Korhonen J, Armstrong E, Alitalo K (1992) Diverse receptors for fibroblast growth factors. Prog Growth Factor Res 4:69-83. 
Peng X, Greene LA, Kaplan DR, Stephens RM (1995) Deletion of a conserved juxtamembrane sequence in Trk abolishes NGF-promoted neuritogenesis. Neuron 15:395-406.

Peters K, Ornitz D, Werner S, Williams L (1993) Unique expression pattern of the FGF receptor 3 gene during mouse organogenesis. Dev Biol 155:423-430.

Rydel RE, Greene LA (1987) Acidic and basic fibroblast growth factors promote stable neurite outgrowth and neuronal differentiation in cultures of PC12 cells. J Neurosci 7:3639-3653.

Sasaki K, Oomura Y, Suzuki K, Hanai K, Yagi H (1992) Acidic fibroblast growth factor prevents death of hippocampal CA1 pyramidal cells following ischemia. Neurochem Int 21:397-402.

Schlessinger J, Bar-Sagi D (1994) Activation of ras and other signaling pathways by tyrosine receptor kinases. In: Symposia on quantitative biology: molecular genetics of cancer, Vol 60, pp 73-79. Cold Spring Harbor, NY: Cold Spring Harbor Laboratory.

Schubert D, Ling N, Baird A (1987) Multiple influences of a heparinbinding growth factor on neuronal development. J Cell Biol 104:635-643.

Sendtner M, Arakawa Y, Stoeckli KA, Kreutzberg GW, Thoenen H (1991) Effect of ciliary neurotrophic factor (CNTF) on motoneuron survival. J Cell Sci [Suppl] 15:103-109.

Shaoul E, Reich-Slotky R, Berman B, Ron D (1995) Fibroblast growth factor receptors display both common and distinct signaling pathways. Oncogene 10:1553-1561.

Stemple DL, Mahanthappa NK, Anderson DJ (1988) Basic FGF induces neuronal differentiation, cell division, and NGF dependence in chromaffin cells: a sequence of events in sympathetic development. Neuron $1: 517-525$.

Thomas SM, DeMarco M, D’Arcangelo G, Halegoua S, Brugge JS (1992) Ras is essential for nerve growth factor- and phorbol ester-induced tyrosine phosphorylation of MAP kinases. Cell 68:1031-1040.

Thompson LM, Plummer S, Schalling M, Altherr MR, Gusella JF, Housman DE, Wasmuth JJ (1991) A gene encoding a fibroblast growth factor receptor isolated from the Huntington disease gene region of human chromosome 4. Genomics 11:1133-1142.

Togari A, Dickens G, Kuzuya H, Guroff G (1985) The effect of fibroblast growth factor on PC12 cells. J Neurosci 5:307-316.
Traverse S, Seedorf K, Paterson H, Marshall CJ, Cohen P, Ullrich A (1994) EGF triggers neuronal differentiation of PC12 cells that overexpress the EGF receptor. Curr Biol 4:694-701.

Unsicker K, Reichert-Preibsch H, Schmidt R, Pettmann B, Labourdette G, Sensenbrenner M (1987) Astroglial and fibroblast growth factors have neurotrophic functions for cultured peripheral and central nervous system neurons. Proc Natl Acad Sci USA 84:5459-5463.

Vaillancourt RR, Heasley LE, Zamarripa J, Storey B, Valius M, Kazlauskas A, Johnson GL (1995) Mitogen-activated protein kinase activation is insufficient for growth factor receptor-mediated PC12 cell differentiation. Mol Cell Biol 15:3644-3653.

Vicario-Abejón C, Johe KK, Hazel TG, Collazo D, Mckay RDG (1995) Functions of basic fibroblast growth factor and neurotrophins in the differentiation of hippocampal neurons. Neuron 15:105-114.

Walicke P, Cowan WM, Ueno N, Baird A, Guillemin R (1986) Fibroblast growth factor promotes survival of dissociated hippocampal neurons and enhances neurite extension. Proc Natl Acad Sci USA 83:3012-3016.

Wanaka A, Johnson Jr EM, Milbrandt J (1990) Localization of FGF receptor mRNA in the adult rat central nervous system by in situ hybridization. Neuron 5:267-281.

Wang JK, Goa G, Goldfarb M (1994) Fibroblast growth factor receptors have different signaling and mitogenic potentials. Mol Cell Biol 14:181-188.

Wood KW, Qi H, D'Arcangelo G, Armstrong RC, Roberts TM, Halegoua $S$ (1993) The cytoplasmic raf oncogene induces a neuronal phenotype in PC12 cells: a potential role for cellular raf kinases in neuronal growth factor signal transduction. Proc Natl Acad Sci USA 90:5016-5020.

Yayon A, Klagsbrun M, Esko JD, Leder P, Ornitz DM (1991) Cell surface, heparin-like molecules are required for binding of basic fibroblast growth factor to its high affinity receptor. Cell 64:841-848.

Yazaki N, Hosoi Y, Kawabata K, Miyake A, Minami M, Satoh M, Ohta M, Kawasaki T, Itoh N (1994) Differential expression patterns of mRNA for members of the fibroblast growth factor receptor family, FGFR-1FGFR-4, in rat brain. J Neurosci Res 37:445-452. 